\title{
chemometrics conference
}

\section{Topical Issue: Chemometrics}

This issue of the NBS Journal of Research is devoted entirely to one topic:

Chemometrics. A conference by that title held earlier this year at NBS brought together experts in analytical chemistry and applied mathematics, disciplines which are the constituents of this new field. This conference was probably the first one in the United States by that title.

The roots of the interdisciplinary effort go back to the late Dr. William (Jack) Youden and we dedicate this issue to him. A brief description of Youden's career serves as the introduction to the collection of conference papers which we present in this volume of the Journal. The authors of this biographical sketch, Drs. Ku and DeVoe, worked very closely with Youden while he was at NBS.

With the publication of the papers presented at this conference we hope to stimulate further work in the field of chemometrics. Special recognition goes to the organizers of the conference who also served as invited editors of this special issue of the NBS Journal of Research: Drs. Clifford H. Spiegelman of the Center for Applied Mathematics, Robert L. Watters of the Center for Analytical Chemistry, and Jerome Sacks from the University of Illinois.

Hans J. Oser Chief Editor 